\title{
Geodetic evidence of viscoelastic relaxation after the 2008 Iwate-Miyagi Nairiku earthquake
}

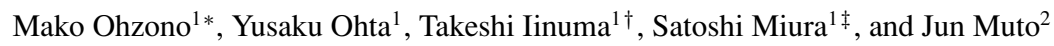 \\ ${ }^{1}$ Research Center for Prediction of Earthquakes and Volcanic Eruptions, Graduate School of Science, Tohoku University, Japan \\ ${ }^{2}$ Department of Earth Science, Tohoku University, Japan
}

(Received July 20, 2010; Revised April 2, 2012; Accepted April 2, 2012; Online published September 18, 2012)

\begin{abstract}
Continuous GPS observations, for over two years, detected long-term postseismic deformation after the 2008 Iwate-Miyagi Nairiku earthquake $\left(M_{\mathrm{j}} 7.2\right)$. The displacement field exhibits ESE-WNW shortening and subsidence near the focal area. These features are attributed to a viscoelastic relaxation caused by the mainshock. A simple two-layered structural model, which consists of an elastic layer having a thickness of 19.0-23.5 km and an underlying Maxwell viscoelastic layer having a viscosity of $2.4-4.8 \times 10^{18} \mathrm{~Pa}$ s, explains the far-field deformation pattern, which probably reflects the viscoelastic response exclusively. These estimated parameters are consistent with the deeper limit of the seismogenic layer in the upper crust and the previous rheological model in northeastern Japan. However, near-field deformation requires additional sources in order to reproduce the observed postseismic deformation, such as long-term afterslip and/or a complicated response due to the highly heterogeneous structure suggested by seismic tomography studies.
\end{abstract}

Key words: Geodetic observation, postseismic deformation, viscoelastic response, inland earthquake.

\section{Introduction}

It is important to understand the rheological structure of the crust and the mantle, which affects the tectonic loading beneath an active fault region. Space-based geodetic measurements are an indispensable tool for directly and precisely measuring spatiotemporal crustal deformation. This monitoring permits the detection of the crustal deformation induced by underground viscoelastic behavior.

We herein investigate the possibility of viscoelastic relaxation caused by the 2008 Iwate-Miyagi Nairiku (inland) earthquake $\left(M_{\mathrm{j}} 7.2\right.$, hereinafter IMNE) using 800 days of global positioning system (GPS) data. The IMNE occurred just beneath the Ou Backbone range (OBR) on 13 June, 2008 (UTC). This region is a part of the volcanic front extending along northeastern Japan (Fig. 1) and a high-strainrate zone is suggested based on continuous GPS monitoring (Miura et al., 2004). This high-strain-rate zone is thought to be caused by a weakening of the lower crust or upper mantle due to an upwelling flow of fluid in the mantle wedge originating from the subducting oceanic slab (Hasegawa et al., 2005). Therefore, the lower crust or upper mantle beneath the OBR is thought to be weaker than in other regions. This interpretation is demonstrated by means of a numerical sim-

\footnotetext{
*Now at Institute of Seismology and Volcanology, Graduate School of Science, Hokkaido University, Japan.

${ }^{\dagger}$ Now at International Research Institute of Disaster Science, Tohoku University, Japan.

${ }^{\ddagger}$ Now at Earthquake Research Institute, University of Tokyo, Japan.

Copyright (c) The Society of Geomagnetism and Earth, Planetary and Space Sciences (SGEPSS); The Seismological Society of Japan; The Volcanological Society of Japan; The Geodetic Society of Japan; The Japanese Society for Planetary Sciences; TERRAPUB.
}

doi: $10.5047 /$ eps.2012.04.001 ulation (Shibazaki et al., 2008), in which geophysical data such as crust and upper mantle velocity structure, and the geothermal gradient, are considered. Muto (2011) also discusses the rheological structure taking rock mechanics in northeastern Japan into account. His rheological structure reflects the patterns of current geodetic strain accumulation and of shallow seismicity.

Based on GPS measurements, Ohta et al. (2008a) reported the coseismic displacement field of the IMNE and constructed a simple model consisting of two rectangular faults. Iinuma et al. (2009) analyzed one-month GPS data from pre-existing networks and prompt postseismic observation, and they found significant postseismic deformation caused by remarkable aseismic slip lasting for two weeks in the shallower part of the earthquake fault and the Dedana fault (DF in Fig. 1). Even though this fault is a part of the inland active fault zone located along the eastern margin of the OBR and is very close to the source area (approximately $20 \mathrm{~km}$ ), no coseismic displacement occurred during the IMNE mainshock (Ohta et al., 2008a).

Three possible mechanisms, namely afterslip, viscoelastic relaxation and poroelastic rebound (e.g., Feigl and Thatcher, 2006) may account for the postseismic deformation. Although the postseismic deformations of recent Japanese inland earthquakes observed based on GPS measurements have already been discussed (e.g., Takahashi et al., 2005; Iinuma et al., 2008; Ohta et al., 2008b), they assumed only afterslip rather than viscoelastic relaxation or poroelastic rebound. There may be two reasons why they did not consider viscoelastic relaxation: either the effect was too weak to examine or the observation period (a few months) was too short to detect the viscoelastic relaxation, which has a relatively long decay time (several 


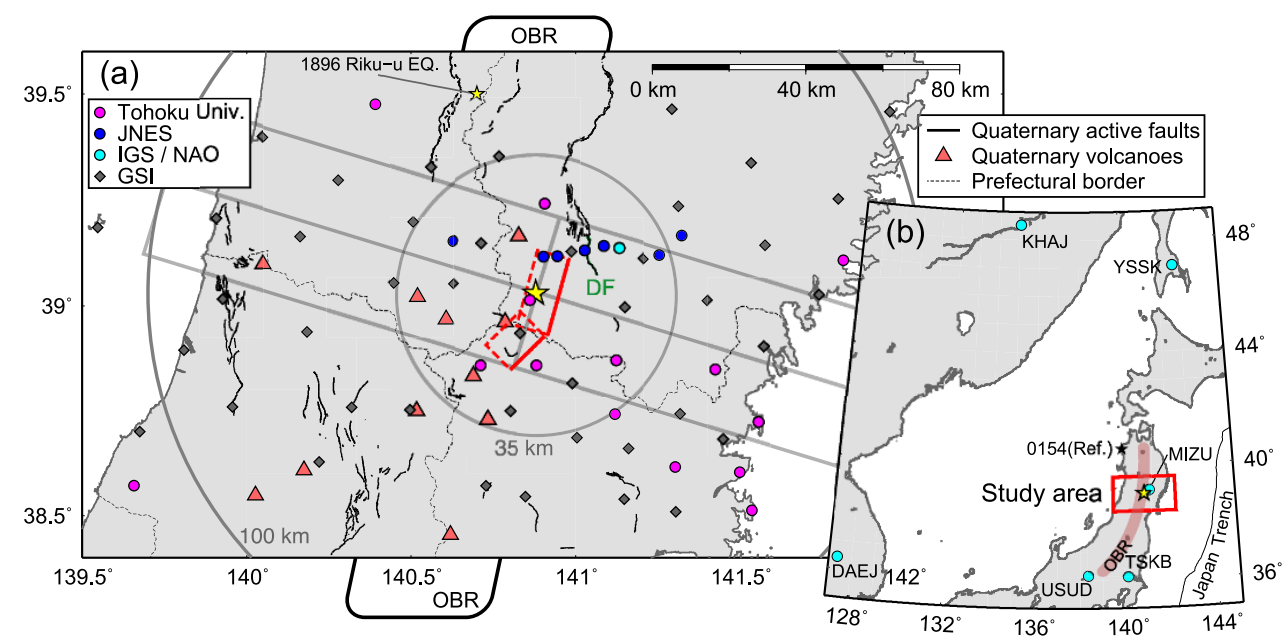

Fig. 1. Global positioning system network used in this study. (a) Enlarged map of the rectangle in (b). The circles and diamonds indicate GPS sites operated by Tohoku University, the Japan Nuclear Energy Safety Organization (JNES), the International GNSS Service (IGS), the National Astronomical Observatory (NAO), and the Geospatial Information Authority (GSI), as indicated at the top-left. The epicenters of the 2008 Iwate-Miyagi Nairiku and 1896 Riku-u earthquakes are indicated by stars in the central and northern parts of the map, respectively. The two rectangles denote the earthquake faults estimated by Ohta et al. (2008a). The displacement profiles shown in Figs. 2(c) and 2(d) are drawn along the long centerline of the gray rectangle. The gray solid lines show the epicentral distance of $35 \mathrm{~km}$ and $100 \mathrm{~km}$, respectively.

years to decades). Viscoelastic relaxation after large inland earthquakes of $M>7$ appears to continue for several years to a few decades in the Tohoku region. Suito and Hirahara (1999) and Thatcher et al. (1980) investigated the viscoelastic relaxation caused by the 1896 Riku-u earthquake (M 7.2) and suggested Maxwell times of 5 years and 20 years, respectively. On the other hand, the signal of poroelastic rebound is thought to be small. According to a calculation by Iinuma et al. (2009), the displacement induced by the poroelastic rebound is much smaller than other processes after the IMNE $(<1 \mathrm{~mm}$, which is less than one order of magnitude). Therefore, we assume poroelastic effect to be negligible in the present study.

Taking the possibility of ductile flow into account, we expect postseismic deformation after the IMNE in response to the potentially low viscosity in the lower crust and/or upper mantle, which is indicated by a seismic low-velocity (Hasegawa et al., 2005). Using GPS data for a longer duration with a dense observation network might provide independent information on the rheological structure, in addition to that obtained from seismological studies.

In the present paper, we first explain how to extract the postseismic deformation signal from GPS coordinate time series. We describe the characteristics of the postseismic deformation field and the relationship to the viscoelastic relaxation. Finally, we estimate the rheological structure using a simple two-layered viscoelastic Earth model and validate our estimations by a comparison with previous studies.

\section{GPS Data}

We estimated the four-year GPS daily coordinates (January 1, 2006-December 31, 2009) through baseline analysis using the Bernese GPS Software version 5.0 (Dach et al., 2007). The analyzed GPS sites are shown in Fig. 1. We used the final precise satellite orbits and the Earth orientation parameters provided by the International GNSS Service (IGS). The daily coordinates are constrained with the
International Terrestrial Reference Frame 2008 (Altamimi et al., 2011) at five IGS sites around northeastern Japan (Fig. 1(b)). Since an IGS site (MIZU) is close to the focal area, we do not constrain this site, but rather perform analysis in the same manner as for the other observation sites. In order to eliminate regional common-mode noise, the coordinate time series are taken relative to a Geospatial Information Authority (GSI) site 0154 (Fig. 1(b)).

The daily coordinate time series after the IMNE includes not only the postseismic deformation signal but also the linear trend due to tectonic motion and seasonal variation caused by various factors. Therefore, we express these secular and seasonal components as follows:

$$
\begin{gathered}
u(t)=a t+b+c \sin (2 \pi t)+d \cos (2 \pi t) \\
+e \sin (4 \pi t)+f \cos (4 \pi t),
\end{gathered}
$$

where $t$ is time in years. In order of appearance, each two terms indicate linear, annual, and semi-annual components, respectively. We estimated the coefficients of each term in Eq. (1) using a least-squares fitting from coordinate time series before the IMNE (January 1, 2006-June 12, 2008). In the estimation of the coefficients, the use of long-period data to explain stable steady crustal movement is preferable. However, a moderate interplate earthquake occurred at the southeast region of the study area on 16 August 2005 (M 7.2, Miyagi-oki earthquake, e.g., Miura et al., 2006). Thus, we consider only the data after 2006 , when the postseismic effect can be considered to be negligible. Using these estimated coefficients, we define the steady trend of the postseismic period. We introduce the assumption that the steady trend does not change before or after the IMNE in this study.

The postseismic deformation signal is extracted by subtracting the steady trend from the observed coordinate time series. The seven sites, however, which are indicated as JNES (Japan Nuclear Energy Safety Organization) in Fig. 1, were fitted only with the linear term, because these sites 
(a)
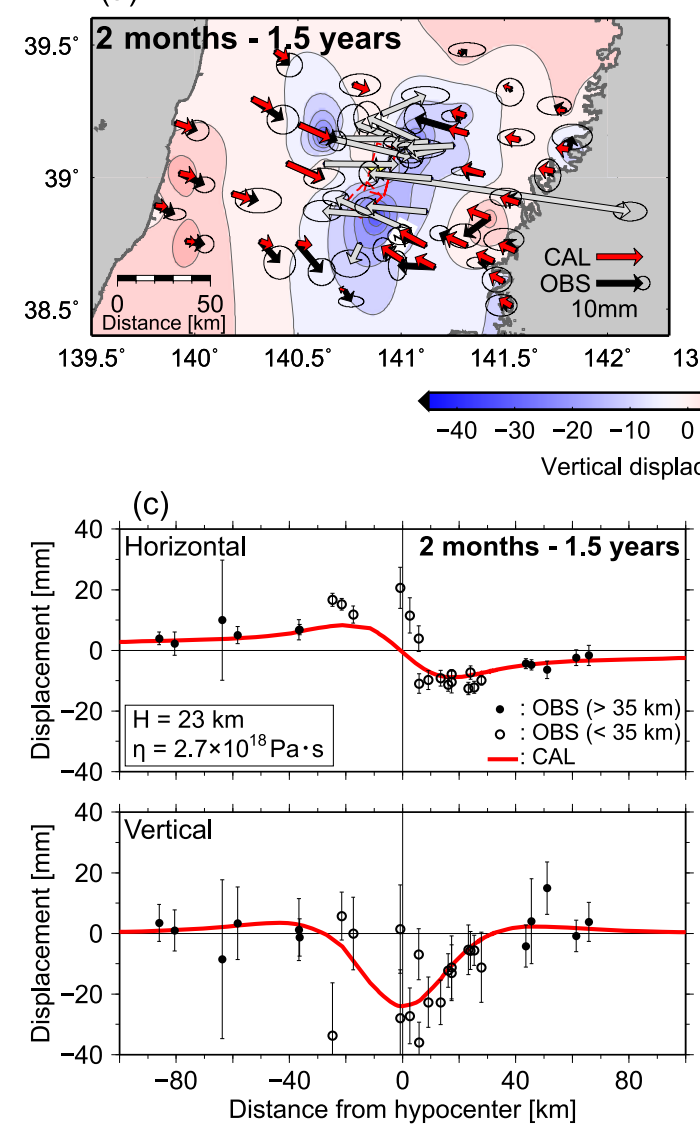

(b)

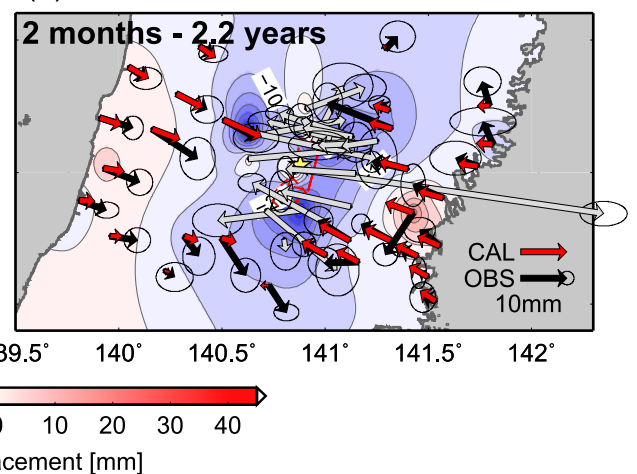

(d)
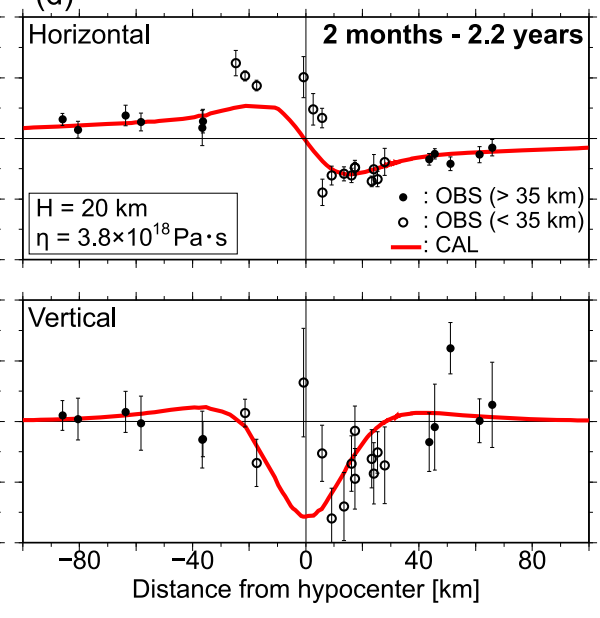

Fig. 2. Postseismic displacement field of (a) 2 months to 1.5 years and (b) 2 months to 2.2 years after the IMNE. The black and gray vectors are observations at GPS sites, which are located over $35 \mathrm{~km}$, and within $35 \mathrm{~km}$, from the epicenter, respectively. The red vectors are the displacements predicted with the optimal elastic thickness and the viscosity of the viscoelastic layer. The color contour lines indicate vertical displacement. The blue and red contour lines indicate subsidence and uplift, respectively. (c) Horizontal (upper) and vertical (bottom) displacement profile of the 1.5-yr data. The profile crosses the epicenter in the $\mathrm{N} 107^{\circ} \mathrm{E}$ direction. The profiled line is along the centerline of the gray rectangle shown in Fig. 1(a). The red line is predicted by optimum parameters. The plotted observation sites are located within $20 \mathrm{~km}$ from the centerline. The solid circles, which are located over $35 \mathrm{~km}$ from the epicenter, are used for prediction, and the open circles are not used for prediction. The error bars show 1- $\sigma$ errors. (d) Same as (c), but for the 2.2-yr data.

were constructed just eight months before the IMNE mainshock and so it is difficult to estimate the accurate annual and semi-annual components.

For checking the reliability of the estimated rheological structure based on the postseismic time series, we use two different analysis periods: one from two months after the mainshock to 547 days ( 1.5 years, hereinafter 1.5 -yr) after the mainshock (August 13, 2008-December 13, 2009), and the other from two months after the mainshock to 800 days (approximately 2.2 years, hereinafter 2.2-yr) after the mainshock (August 13, 2008-December 13, 2009). The postseismic displacement for these time periods are calculated by taking the averages for five days at each epoch. Generally, several causes of postseismic deformation affect coordinate time series immediately after the mainshock. Therefore, we focus on only the viscoelastic response by omitting the data during two months after the mainshock.

\section{Estimation of Viscoelastic Structure Based on Postseismic Deformation}

Two time periods of the horizontal and vertical deformation field are shown in Figs. 2(a) and 2(b) with vectors (black and gray) and color contour lines, respectively. The horizontal displacements over the whole region are directed towards the focal area, while the subsidence is distributed around the source area. Both the overall horizontal displacement pattern and the local subsidence can be ascribed to a viscoelastic response (e.g., Thatcher et al., 1980). It is difficult to interpret these observations by assuming afterslip or poroelastic rebound, which reproduces the deformation pattern limited within a narrow area near the focal area. Furthermore, if afterslip occurs on the coseismic fault, or neighboring faults, then a local uplift should be observed around the up-dip end of the afterslip faults because the IMNE was a reverse-fault earthquake. The observation results, however, exhibit subsidence in and around the focal area. The poroelastic rebound effect is expected only near the focal area, and its magnitude should be much smaller than that caused by other postseismic sources (Iinuma et al., 2009). Therefore, the viscoelastic response may be the primary factor of the observed long-term deformation. As such, we propose a simple rheological model to reproduce the observation results for the two periods.

We construct a simple spherical two-layered model to reproduce the observation under the assumption that the observed postseismic deformation is caused by viscoelas- 
Table 1. Physical properties in the elastic layer and underlying viscoelastic layer of the present study and previous studies.

\begin{tabular}{|c|c|c|c|c|c|c|}
\hline & $\begin{array}{c}\text { Rigidity } \\
\text { [GPa] }\end{array}$ & $\begin{array}{c}\text { Bulk modulus } \\
{[\mathrm{GPa}]}\end{array}$ & $\begin{array}{l}\text { Density } \\
{\left[\mathrm{kg} / \mathrm{m}^{3}\right]}\end{array}$ & $\begin{array}{c}\text { Thickness } \\
{[\mathrm{km}]}\end{array}$ & $\begin{array}{c}\text { Viscosity } \\
{[\mathrm{Pa} \mathrm{s}]}\end{array}$ & $\begin{array}{c}\text { Maxwell time } \\
\text { [Year] }\end{array}$ \\
\hline \multicolumn{7}{|l|}{ Elastic layer } \\
\hline Present study $1.5 \mathrm{yr}$ & 30 & 50 & $2.8 \times 10^{3}$ & $19.5-25.5$ & $\infty$ & - \\
\hline Present study $2.2 \mathrm{yr}$ & 30 & 50 & $2.8 \times 10^{3}$ & $17.0-23.5$ & $\infty$ & - \\
\hline Suito and Hirahara (1999) & 30 & 49 & - & 30 (fixed) & $\infty$ & - \\
\hline Thatcher et al. (1980) & 30 & - & - & 30 & $\infty$ & - \\
\hline \multicolumn{7}{|l|}{ Elastic layer } \\
\hline Present study $1.5 \mathrm{yr}$ & 60 & 100 & $3.3 \times 10^{3}$ & 440 & $2.4-3.4 \times 10^{18}$ & $1.3-1.8$ \\
\hline Present study $2.2 \mathrm{yr}$ & 60 & 100 & $3.3 \times 10^{3}$ & 440 & $3.1-4.8 \times 10^{18}$ & $1.6-2.5$ \\
\hline Suito and Hirahara (1999) & 59 & 110 & - & $250-265$ & $9.0 \times 10^{18}$ & 5 \\
\hline Thatcher et al. (1980) & 30 & - & - & $\infty$ & $1-6 \times 10^{20}$ & 20 \\
\hline
\end{tabular}
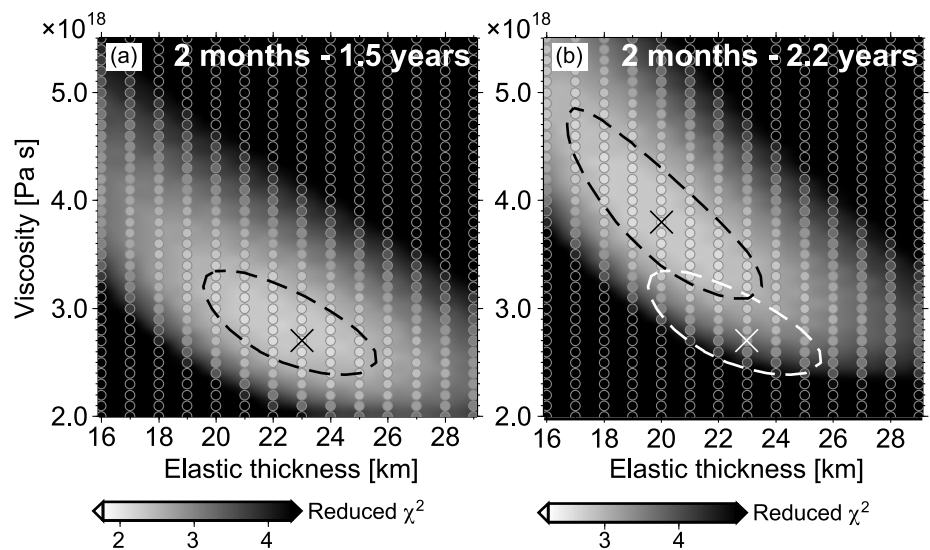

Fig. 3. Reduced $\chi^{2}$ distributions obtained by grid search for (a) 1.5 -yr and (b) 2.2-yr data. The vertical and horizontal axes indicate the viscosity of the viscoelastic layer and the elastic thickness, respectively. The small circles indicate calculated points. The grey scale represents a reduced $\chi^{2}$ value. The dashed contour line indicates the confidence limit of 1- $\sigma$. For comparison, the same dashed contour line of (a) is plotted in (b) in white.

tic relaxation. We use the VISCO1D code developed by Pollitz (1997) to calculate the surface deformation caused by the viscoelastic response. The two-layered model consists of an elastic layer representing the upper crust overlying a Maxwell viscoelastic substratum, which represents the lower crust and the upper mantle. For the initial coseismic step due to the mainshock, we use the coseismic fault model proposed by Ohta et al. (2008a). Structural parameters such as rigidity, bulk modulus, and density (of the elastic layer and the viscoelastic substratum) used in our numerical calculation are summarized in Table 1. The thickness of the elastic layer and the viscosity of the underlying layer are estimated by the grid search as unknown parameters optimization, so as to minimize the reduced $\chi^{2}$ value (e.g., Press et al., 1992) by assuming these parameters to be in the range between 17 and $35 \mathrm{~km}$ and $1.0 \times 10^{17}$ and $9.0 \times 10^{21} \mathrm{~Pa}$ s, respectively, based on previous studies (e.g., Suito and Hirahara, 1999).

Although we omitted the data for the first two months after the IMNE, as mentioned above, the GPS data may be contaminated by afterslip and/or poroelastic responses. Freed et al. (2006) examined the postseismic signal after the 2002 Denali earthquake (M 7.9) in Alaska taking into account afterslip, poroelastic rebound, and viscoelastic relaxation. They suggested that the far-field data could be interpreted only in terms of viscoelastic relaxation, whereas two other processes are dominant in the near field data. In the present study, we focus on the viscoelastic response by selecting far-field displacement data at 33 GPS sites located at epicentral distances in the range between 35 and $100 \mathrm{~km}$ (Fig. 1(a)). This range is chosen by trial and error by changing the applied area, which minimizes the value of the reduced $\chi^{2}\left(\chi^{2}\right.$ divided by the number of degrees of freedom, which in this case is 97).

The resultant reduced $\chi^{2}$ distribution is shown in Fig. 3 . For the 1.5-yr data, we obtain the optimum elastic thickness and the viscosity as $23 \mathrm{~km}(19.5$ to $25.5 \mathrm{~km}$ with a $1 \sigma$ confidence level) and $2.7 \times 10^{18} \mathrm{~Pa} \mathrm{~s}\left(2.4-3.4 \times 10^{18} \mathrm{~Pa} \mathrm{~s}\right.$ with a $1 \sigma$ confidence level), respectively. The minimum value of the reduced $\chi^{2}$ is 1.63 . For the 2.2-yr data, the optimum elastic thickness and viscosity are $20.0 \mathrm{~km}(17.0$ to $23.5 \mathrm{~km}$ with a $1 \sigma$ confidence level) and $3.8 \times 10^{18}$ Pa s $\left(3.1-4.8 \times 10^{18} \mathrm{~Pa} \mathrm{~s}\right.$ with a $1 \sigma$ confidence level), respectively. The minimum value of the reduced $\chi^{2}$ is 2.13 .

The displacements predicted with these optimum parameters are shown in Figs. 2(a) and 2(b) as red vectors. The displacement profiles crossing the epicenter in the $\mathrm{N} 107^{\circ} \mathrm{E}$ direction, for the 1.5-yr and 2.2-yr data, are shown in Figs. 2(c) and 2(d), respectively. Plotted observed sites are located within $20 \mathrm{~km}$ from the profile line, as indicated by a gray rectangle in Fig. 1(a). For both time periods, the horizontal displacement pattern calculated from our optimum model (solid red lines) shows a good agreement with the observed displacement (black and white circles), especially 
further than $35 \mathrm{~km}$ from the epicenter. Even though the observed vertical displacement has a large error, our model roughly explains the data distribution and the profile pattern. Therefore, the viscoelastic process with the estimated parameters is appropriate for the interpretation of the observed far-field postseismic displacement. In contrast, it is difficult to explain the near field data (white circles in Fig. 2) around the epicenter, especially in their horizontal components.

\section{Discussion}

The estimated parameters in the present study are roughly consistent with those reported in previous studies (see Table 1). The east-west profile of crustal seismicity, shown by Tanaka and Ishikawa (2002), suggests that the deeper limit of the seismicity is approximately $20 \mathrm{~km}$, except for the volcanic region (OBR). This value agrees with the elastic thickness obtained in the present study. Because we use GPS sites further than $35 \mathrm{~km}$ from the epicenter, it is thought that this thickness of the elastic layer indicates an averaged value around the whole study area (Tohoku region) except for the focal area. Therefore, it appears that the estimated thickness of the elastic layer $(19-23.5 \mathrm{~km})$ corresponds to the seismogenic layer. The current result is consistent with the strength profile by Muto (2011) whose brittle-ductile transition zone is located at $18-28-\mathrm{km}$ depth off the OBR.

Hasegawa et al. (2000), however, showed that the depth limit of shallow seismic events is approximately $15 \mathrm{~km}$ or less along the OBR. In addition, Nakajima et al. (2001) clarified the distinct heterogeneity of the seismic velocity distribution in the crust and upper mantle in the study area. This heterogeneity is attributed to the plate subduction process (Hasegawa et al., 2005). Focusing on the surrounding region of the IMNE source area, Okada et al. (2010) examined the relationship between the heterogeneous velocity structure and the aftershock distribution. The locations of volcanoes and active faults were determined through a high-resolution seismic tomography study and it was found that the low-velocity zones beneath the focal area and the surrounding volcanoes can be traced to the mantle wedge. We may expect a viscoelastic property in these low-velocity zones and, consequently, a thinner elastic thickness locally beneath the focal area. This heterogeneous velocity structure may reflect a complex rheological structure, which may be one of the reasons for the localized discrepancy near the focal area between observation and our model (see Fig. 2). From laboratory measurements of the seismic velocity of various rocks under high pressure and temperature, Nishimoto et al. (2008) have concluded that the low velocity zone in the lower crust beneath the OBR has a raised temperature locally and is thus partially molten. Using their petrological interpretation, and recent developments in rock mechanics, Muto (2011) predicted the viscosity of the partially molten lower crust beneath the OBR to be $\sim 10^{19} \mathrm{~Pa} \mathrm{~s}$, which is roughly consistent with our estimation.

Unfortunately, it is impossible to evaluate the effect of these heterogeneities by the simple layered model adopted in the present study. We will consider these factors in our future work.
Thatcher et al. (1980) and Suito and Hirahara (1999) investigated the viscoelastic deformation induced by the 1896 Riku-u earthquake ( $M 7.2)$, the epicenter of which is located only $60 \mathrm{~km}$ northwest of the epicenter of the IMNE (Fig. 1(a)). In order to explain the leveling data for 70 years after the Riku-u earthquake, Thatcher et al. (1980) and Suito and Hirahara (1999) estimated the viscosity of the viscoelastic layer, which is deeper than $30 \mathrm{~km}$, to be 1$6 \times 10^{20} \mathrm{~Pa} \mathrm{~s}$ and $9.0 \times 10^{18} \mathrm{~Pa} \mathrm{~s}$, respectively (Table 1 ). The difference in the estimated viscosity probably depends on the calculation method. The result of Suito and Hirahara (1999) is the same order of our result $\left(10^{18} \mathrm{~Pa} \mathrm{~s}\right)$ even though they fixed the elastic thickness $(30 \mathrm{~km})$, and their approach (finite-element-method calculation) differs from that used in the present study. In addition, Suito and Hirahara (1999) also tested the effect of the Pacific slab geometry. They show that consideration of the slab geometry is reasonable to explain the spatial displacement pattern. For more detail, it is necessary to consider a three-dimensional structure that may affect the viscosity estimation.

For both periods, the estimated elastic thickness becomes approximately $20 \mathrm{~km}$ (Fig. 3). Considering the $1-\sigma$ confidence limits, there appear to be no clear differences between their values of elastic thickness (19.5 to $25.5 \mathrm{~km}$ from 1.5-yr data and 17.0 to $23.5 \mathrm{~km}$ from 2.2-yr data, respectively). On the other hand, the 2.2-yr data for viscosity in the viscoelastic layer is estimated to be 1.3 times larger than that of the 1.5-yr data (Fig. 3). This indicates a temporal change of the viscosity in the lower crust or the upper mantle. Freed et al. (2006) predicted that the viscosity beneath the lower crust will become larger over time and will return to a steady state $\left(\sim 10^{19} \mathrm{~Pa} \mathrm{~s}\right) 50$ years after the 2002 Denali earthquake. It might be possible to verify whether this temporal viscosity change is significant by using more varied and longer periods of data. However, the 2011 off the Pacific coast of Tohoku Earthquake ( $M 9.0)$, occurred on the 11 March, 2011 (e.g., Ide et al., 2011; Iinuma et al., 2011). The large coseismic displacement, following postseismic deformation and large aftershocks (e.g., Ohta et al., 2011) will practically disable the accurate GPS time series treatment for such a small amount of viscoelastic relaxation of the IMNE. We need to consider the long-term viscoelastic response around the OBR considering both the effect of the 2008 IMNE and the 2011 off the Pacific coast of Tohoku Earthquake by geodetic surveys.

A number of issues remain to be solved. The large residuals are conspicuous near the focal area because we did not use near-field data, as described in previous sections. In Fig. 2, a large postseismic deformation is dominant near the focal area, even two months after the mainshock. For further investigation of this point, we must reproduce the observations as far as possible by taking into account factors such as the lateral heterogeneity of the elastic layer thickness and/or the viscosity of the substratum. The long-term afterslip that demonstrates a similar deformation pattern to the coseismic slip caused by a reverse faulting, as shown by Ohta et al. (2008a), might be a potential source of the large residuals. This means that we need to incorporate additional model parameters for long-term afterslip in order to reproduce the overall observations during the postseismic period. 


\section{Conclusions}

We have proposed a viscoelastic response following the 2008 IMNE which continues for more than 2.2 years. A simple two-layered model consisting of an elastic layer having a thickness of 19 to $23.5 \mathrm{~km}$ and an underlying Maxwell viscoelastic layer with a viscosity of $2.4-4.8 \times 10^{18} \mathrm{~Pa}$ s explains the far-field deformation pattern. The elastic layer thickness agrees with the deeper limit of crustal seismicity in the study area. The estimated viscosity is approximately consistent with values reported in previous studies. A detailed study considering the highly-heterogeneous viscoelastic structure, which corresponds to a seismic velocity anomaly, and/or multiple causalities, in addition to the viscoelastic response, is indispensable for understanding the overall postseismic process in the study area, leading to an understanding of island arc deformation in subduction zones.

Acknowledgments. GPS data were provided by a research project conducted by the Japanese Nuclear Energy Safety Organization (JNES) in order to establish the evaluation techniques of seismogenic faults, the Geospatial Information Authority of Japan, and the Mizusawa VLBI Observatory of the National Astronomical Observatory of Japan. We would like to thank K. Tachibana, T. Sato, and Dr. T. Demachi for their efforts in maintaining the GPS sites at Tohoku University. In addition, we would like to thank Dr. A. Freed and Dr. T. Sato for the useful discussion. We are also grateful to Dr. H. Suito and an anonymous reviewer, and editor Dr. T. Sagiya for useful discussions and comments to improve this paper. The present study was partly supported by a Grant-inAid for JSPS Fellows (No. 2056071) and Grant-in-Aid for Young Scientists (B: No. 22740287).

\section{References}

Altamimi, Z., X. Collilieux, and L. Métivier, ITRF2008: an improved solution of the international terrestrial reference frame, J. Geod., doi:10.1007/s00190-011-0444-4, 2011.

Dach, R., U. Hugentobler, P. Fridez, and M. Meindl, User Manual of the Bernese GPS Software Version 5.0, pp. 640, Astronomical Institute, University of Bern, 2007.

Feigl, K. and W. Thatcher, Geodetic observations of post-seismic transients in the context of the earthquake deformation cycle, C. R. Geosci., 338, 1012-1028, doi:10.1016/j.crte.2006.06.006, 2006.

Freed, A. M., R. Buürgmann, E. Calais, and J. Freymueller, Stressdependent power-law flow in the upper mantle following the 2002 Denali, Alaska, earthquake, Earth Planet. Sci. Lett., 252, 481-489, doi:10.1016/j.eps1.2006.10.011, 2006.

Hasegawa, A., A. Yamamoto, N. Umino, S. Miura, S. Horiuchi, D. Zhao, and H. Sato, Seismic activity and deformation process of the overriding plate in the northeastern Japan subduction zone, Tectonophysics, 319, 225-239, doi:10.1016/S0040-1951(99)00296-6, 2000

Hasegawa, A., J. Nakajima, N. Umino, and S. Miura, Deep structure of the northeastern Japan arc and its implications for crustal deformation and shallow seismic activity, Tectonophysics, 403, 59-75, doi:10.1016/j.tecto.2005.03.018, 2005.

Ide, S., A. B. Baltay, and G. C. Beroa, Shallow dynamic overshoot and energetic deep rupture in the $2011 \mathrm{Mw} 9.0$ Tohoku-Oki earthquake, Science, doi:10.1126/science.1207020, 2011.

Iinuma, T., Y. Ohta, S. Miura, K. Tachibana, T. Matsushima, H. Takahashi, T. Sagiya, T. Ito, S. Miyazaki, R. Doke, A. Takeuchi, K. Miyao, A. Hirao, T. Maeda, T. Yamaguchi, M. Takada, M. Iwakuni, T. Ochi, I. Meilano, and A. Hasegawa, Postseismic slip associated with the 2007 Chuetsu-oki, Niigata, Japan, Earthquake (M 6.8 on 16 July 2007) as inferred from GPS data, Earth Planets Space, 60, 1087-1091, 2008.

Iinuma, T., M. Ohzono, Y. Ohta, S. Miura, M. Kasahara, H. Takahashi, T. Sagiya, T. Matsushima, S. Nakao, S. Ueki, K. Tachibana, T. Sato, H. Tsushima, K. Takatsuka, T. Yamaguchi, M. Ichiyanagi, M. Takada, K. Ozawa, M. Fukuda, Y. Asahi, M. Nakamoto, Y. Yamashita, and N. Umino, Aseismic slow slip on an inland active fault triggered by a nearby shallow event, the 2008 Iwate-
Miyagi Nairiku earthquake (Mw6.8), Geophys. Res. Lett., 36, L20308, doi:10.1029/2009GL040063, 2009.

Iinuma, T., M. Ohzono, Y. Ohta, and S. Miura, Coseismic slip distribution of the 2011 off the Pacific coast of Tohoku Earthquake (M9.0) estimated based on GPS data-Was the asperity in Miyagi-oki ruptured?, Earth Planets Space, 63, 643-648, 2011.

Miura, S., T. Sato, A. Hasegawa, Y. Suwa, K. Tachibana, and S. Yui, Strain concentration zone along the volcanic front derived by GPS observations in NE Japan arc, Earth Planets Space, 56, 1347-1355, 2004.

Miura, S., T. Iinuma, S. Yui, N. Uchida, T. Sato, K. Tachibana, and A. Hasegawa, Co- and post-seismic slip associated with the 2005 Miyagioki earthquake (M7.2) as inferred from GPS data, Earth Planets Space, 58, 1567-1572, 2006.

Muto, J., Rheological structure of northeastern Japan lithosphere based on geophysical observations and rock mechanics, Tectonophysics, 503, 201-206, doi:10.1016/j.tecto.2011.03.002, 2011.

Nakajima, J., T. Matsuzawa, A. Hasegawa, and D. Zhao, Seismic imaging of arc magma and fluids under the central part of northeastern Japan, Tectonophysics, 341, 1-17, doi:10.1016/S0040-1951(01)00181$0,2001$.

Nishimoto, S., M. Ishikawa, M. Arima, T. Yoshida, and J. Nakajima, Simultaneous high P-T measurements of ultrasonic compressional and shear wave velocities in Ichino-megata mafic xenoliths: Their bearings on seismic velocity perturbations in lower crust of northeast Japan arc, J. Geophys. Res., 113, B12212, doi:10.1029/2008JB005587, 2008.

Ohta, Y., M. Ohzono, S. Miura, T. Iinuma, K. Tachibana, K. Takatsuka, K. Miyao, T. Sato, and N. Umino, Coseismic fault model of the 2008 IwateMiyagi Nairiku earthquake deduced by a dense GPS network, Earth Planets Space, 60, 1197-1201, 2008a.

Ohta, Y., S. Miura, T. Iinuma, K. Tachibana, T. Matsushima, H. Takahashi, T. Sagiya, T. Ito, S. Miyazaki, R. Doke, A. Takeuchi, K. Miyao, A. Hirao, T. Maeda, T. Yamaguchi, M. Takada, M. Iwakuni, T. Ochi, I. Meilano, and A. Hasegawa, Coseismic and postseismic deformation related to the 2007 Chuetsu-oki, Niigata Earthquake, Earth Planets Space, 60, 1081-1086, 2008b.

Ohta, Y., S. Miura, M. Ohzono, S. Kita, T. Iinuma, T. Demachi, K. Tachibana, T. Nakayama, S. Hirahara, S. Suzuki, T. Sato, N. Uchida, A. Hasegawa, and N. Umino, Large intraslab earthquake (2011 April 7 M 7.1) after the 2011 off the Pacific coast of Tohoku Earthquake (M 9.0): Coseismic fault model based on the dense GPS network data, Earth Planets Space, 63, 1207-1211, 2011.

Okada, T., N. Umino, and A. Hasegawa, Deep structure of the Ou mountain range strain concentration zone and the focal area of the 2008 Iwate-Miyagi Nairiku earthquake, NE Japan-Seismogenesis elated with magma and crustal fluid, Earth Planets Space, 62, 347-352, 2010.

Pollitz, F. F., Gravitational viscoelastic postseismic relaxation on a layered spherical earth, J. Geophys. Res., 102, 17,921-17,941, doi:10.1029/97JB01277, 1997.

Press, W. H. F., B. P. Flannery, S. A. Teukolsky, and W. T. Vetterling, Numerical Recipes in Fortran 77: The Art of Scientific Computing (Second edition), pp. 992, Cambridge University Press, New York, USA, 1992.

Shibazaki, B., K. Garatani, T. Iwasaki, A. Tanaka, and Y. Iio, Faulting processes controlled by the nonuniform thermal structure of the crust and uppermost mantle beneath the northeastern Japanese island arc, $J$. Geophys. Res., 113, B08415, doi:10.1029/2007JB005361, 2008.

Suito, H. and K. Hiraraha, Simulation of postseismic deformations caused by the 1896 Riku-u earthquake, northeast Japan: Re-evaluation of the viscosity in the upper mantle, Geophys. Res. Lett., 26, 2561-2564, doi:10.1029/1999GL900551, 1999.

Takahashi, H., T. Matsushima, T. Kato, A. Takeuchi, T. Yamaguchi, Y. Kohno, T. Katagi, J. Fukuda, K. Hatamoto, R. Doke, Y. Matsu'ura, and M. Kasahara, A dense GPS observation immediately after the 2004 midNiigata Prefecture earthquake, Earth Planets Space, 57, 661-665, 2005.

Tanaka, A. and Y. Ishikawa, Temperature distribution and focal depth in the crust of the northeastern Japan, Earth Planets Space, 54, 1109-1113, 2002.

Thatcher, W., T. Matsuda, T. Kato, and J. B. Rundle, Lithospheric loading by the 1896 Riku-u earthquake, northeastern Japan: Implications for plate flexure and asthenospheric rheology, J. Geophys. Res., 85, 6429_ 6435,1980 .

M. Ohzono (e-mail: m.ohzono@mail.sci.hokudai.ac.jp), Y. Ohta, T. Iinuma, S. Miura, and J. Muto 